Research, part of a Special Feature on Managing Surprises in Complex Systems

\title{
Disaster Preparation and Recovery: Lessons from Research on Resilience in Human Development
}

\author{
$\underline{\text { Ann S. Masten }}^{1}$ and Jelena Obradovic $^{2}$
}

\begin{abstract}
Four decades of theory and research on resilience in human development have yielded informative lessons for planning disaster response and recovery. In developmental theory, resilience following disaster could take multiple forms, including stress resistance, recovery, and positive transformation. Empirical findings suggest that fundamental adaptive systems play a key role in the resilience of young people facing diverse threats, including attachment, agency, intelligence, behavior regulation systems, and social interactions with family, peers, school, and community systems. Although human resilience research emphasizes the adaptive well-being of particular individuals, there are striking parallels in resilience theory across the developmental and ecological sciences. Preparing societies for major disasters calls for the integration of human research on resilience with the theory and knowledge gained from other disciplines concerned with resilience in complex, dynamic systems, and particularly those systems that interact with human individuals as disaster unfolds.
\end{abstract}

Key Words: resilience; disaster; human development; children; recovery

\section{INTRODUCTION}

Threat of catastrophe looms over the beginning of the 21 st century, which opened with an alarming sequence of massive disasters in the form of terrorist attacks, wars, a tsunami, hurricanes, and outbreaks of disease. The mass media are saturated with stories of a possible flu pandemic and global warming, along with reports of ongoing genocide, terrorism, and natural disaster events. In this context, it is imperative for scientists concerned with adaptive systems in many disciplines to consider what is known and what needs to be known that could inform efforts to prevent or ameliorate the consequences of disaster and promote recovery. In this paper, we highlight lessons gleaned from four decades of research on resilience in human development, with the goal of contributing to integrative resilience-oriented planning for disaster response and recovery.

Observations from the literature on resilience in human development may be broadly applicable to diverse massive-scale disaster situations, such as a flu pandemic, war, or natural disasters, in which interdependent adaptive systems at multiple levels, from cellular to global, face destruction. At the same time, it is clear that the lessons drawn from studies of resilience in human development represent only one potential source of perspectives on resilience that could be integrated to enhance the odds of human resilience in the face of disaster. With respect to this ultimate goal, this article also highlights similarities and differences in the concepts of resilience, transformation, and recovery as applied in human developmental sciences compared to ecology.

\section{Origins of resilience research in human development}

Judging from the legends and tales handed down over the millennia in many cultures, people always have been intrigued by stories about individuals who overcome adversity to succeed in life. However, the systematic study of human resilience began shortly before 1970 and focused almost entirely on young people (Masten 2001, Masten and Obradovic 2006). Research on human resilience emerged around the same time as ecological resilience theory and research (Holling 1973, 
Gunderson 2000), although independently. The coincidence of timing would seem to indicate that conditions were ripe for such ideas to take root across diverse fields.

Pioneering investigators in psychiatry and psychology were searching for the causes of mental illness and other health problems by studying children at risk for psychopathology (Masten 2001). Risk factors included traumatic experiences and chronic adversities, which were often implicated as causal contributors to mental illness and many other problems in human development. However, when investigators followed the lives of at-risk children forward in time, marked variations in outcome became apparent, ranging from serious psychopathology with extremely impaired functioning to remarkable successes in multiple domains of life. Subsequently investigators turned their attention to identifying promotive or protective factors, focusing on the question of "What makes a difference?" Then they began to study potential processes that might explain how promotion or protection works in resilience.

\section{Resilience defined at the individual level in human development}

In developmental science, individual resilience refers to the processes of, capacity for, or patterns of positive adaptation during or following exposure to adverse experiences that have the potential to disrupt or destroy the successful functioning or development of the person (Masten et al. 1990, Masten and Obradovic 2006). This broad conceptual umbrella covers three distinct kinds of phenomena: (1) achieving better than expected outcomes in high-risk groups of people, sometimes referred to as overcoming the odds against healthy development; (2) sustaining competence or maintaining effective functioning under highly adverse conditions, sometimes referred to as stress resistance; and (3) regaining or attaining effective or normal functioning following a period of exposure to traumatic experiences or conditions of overwhelming adversity, often described in terms of recovery, bouncing back, normalization, or selfrighting. The last category includes recovery after a crisis or catastrophe as well as normalization onto positive developmental trajectories in response to improved conditions, such as when a child adopted from deprivation conditions in an orphanage shows accelerated catch-up growth when rearing conditions improve.

In the aftermath of a massive trauma or crisis such as a flu pandemic, natural disaster, or a major act of terrorism, diverse individual adaptive/maladaptive patterns are theoretically possible. Illustrations of key patterns are shown in Fig. 1. These patterns reflect resistance, when a person continues to function well during a crisis; delayed breakdown, when resistance is followed by a breakdown in functioning; normal recovery, with a decline in functioning followed by recovery as the crisis abates; breakdown without, as yet, recovery; positive transformation patterns in which a person improves in the course of a crisis and its aftermath, beginning at a higher or lower level of adaptive functioning; and several negative transformation patterns in which the individual was already functioning poorly and either worsens and recovers or remains about the same, perhaps because of a floor effect. Of course, there are many other possibilities, and an individual could follow a much more complex pattern related to fluctuations in his or her capacity for resilience and the nature of the ongoing adversity exposure.

The overarching theoretical framework for resilience research with children drew on developmental systems theory (Thelen and Smith 1998, Ford and Lerner 1992, Lerner 2006), the principles of developmental psychopathology (Masten 2006), and Bronfenbrenner's ecological model of development (Bronfenbrenner 1979, 1986). From this broad and integrative perspective, resilience arises from processes of interaction across multiple levels of functioning, e.g., from genes to neural systems to relationships to individual-media interaction. Further, a living system must maintain its own functioning or internal systems and also adapt to environmental conditions. The individual is continually interacting with people, objects, information, and other aspects of the unfolding contexts in which the individual's life is embedded. In Bronfenbrenner's model, the individual child interacts directly with people, ideas, and things in his or her microsystems, which include family, peer group, and school systems. The child is also influenced indirectly by the connections of family members, teachers, and others to additional systems, e.g., a parent's work place or a teachers' union, known as "exosystems." On the largest scale, human development is also influenced by the 
Fig. 1. Examples of adaptive and maladaptive patterns in relation to an acute-onset disaster. Overall patterns reflecting resilience are shown with dashed lines. $\mathrm{A}=$ resistance, $\mathrm{B}=$ delayed breakdown, $\mathrm{C}=$ normal response and recovery, $\mathrm{D}=$ breakdown without recovery, $\mathrm{E}$ and $\mathrm{F}=$ positive transformation from higher and lower starting levels of adaptive functioning, $G=$ persistent maladaptive pattern with disaster-related dip in functioning, and $\mathrm{H}=$ unresponsive maladaptive pattern, possibly indicating a floor effect.

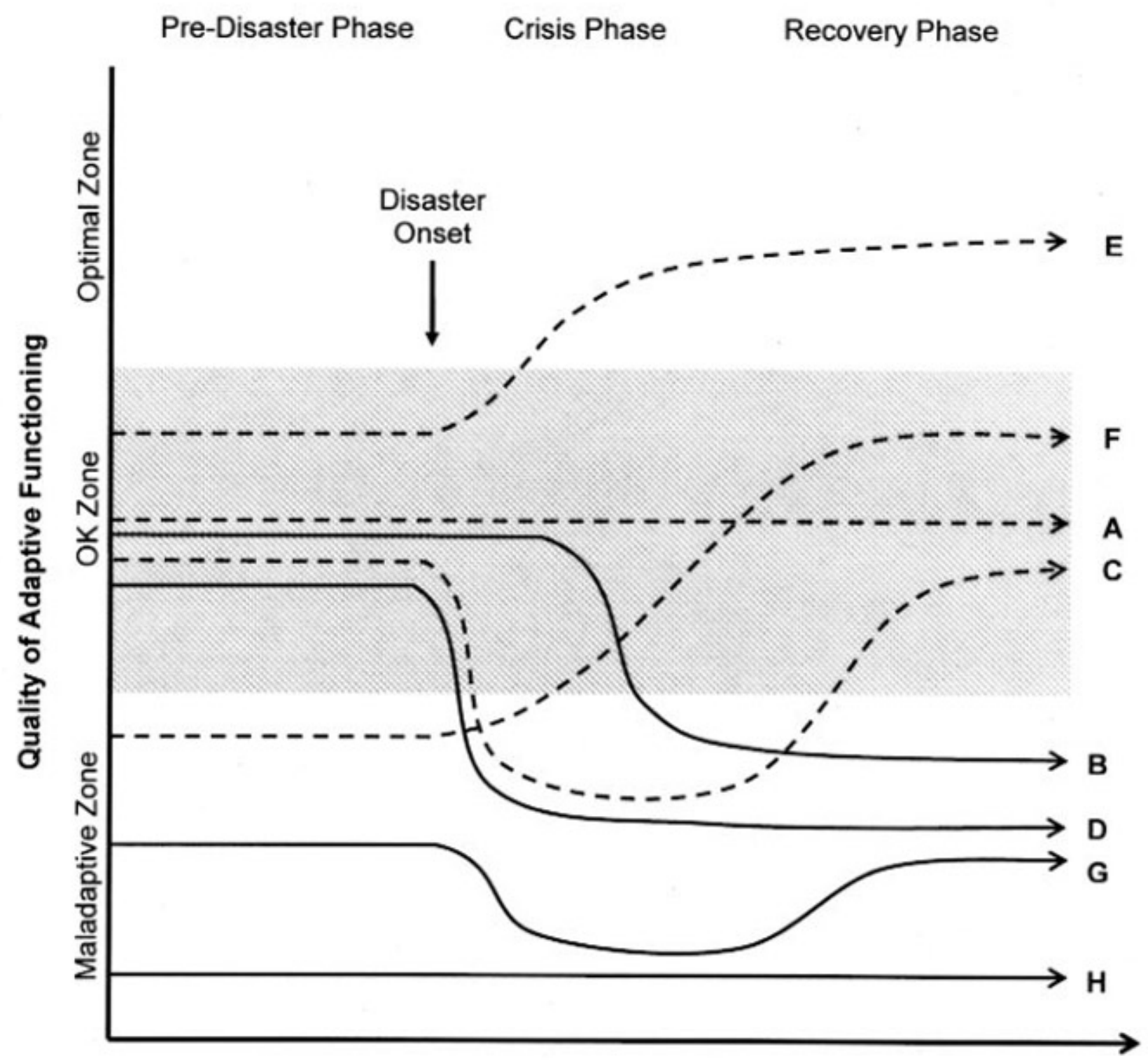

Time 
operations of macrosystems such as community, media, and national policy. Systems functioning within an individual, e.g., the cardiovascular system, immune system, or central nervous system, can also be delineated. Figure 2 illustrates multiple embedded systems both outside and inside a child.

The fact that these systems are embedded, interdependent, and constantly interacting has profound implications for disaster scenarios. Massive disasters are inherently cross-scale in their impact, disrupting functioning across multiple levels of the interdependent socio-cultural systems in which individual human lives are embedded. At the same time, disasters such as hurricanes, bioterrorism, and nuclear accidents are also likely to disrupt ecological and manufactured systems at multiple levels, and there will be many interactions among human/social and nonhuman systems in the course of unfolding disasters.

Whichever pattern of adaptation among individual human organisms or any adaptive living system is under consideration, the determination of resilience always involves two fundamental judgments: (1) the criteria for judging threats or challenges to a system and (2) the criteria for judging the adaptation of a system. To judge resilience, in other words, one must decide (1) whether there has been exposure to significant adversity or risk and (2) whether the person or, more broadly, the living system is functioning effectively and doing what it is supposed to be doing (Masten and Coatsworth 1998, Masten 2001, Luthar 2006). Such judgments always have a time frame, a level of analysis, and a historical context as well as value systems attached to them. The time frame and scale of analysis are often related to each other as well as to the nature of the threat. Maintaining effective cognitive functioning and taking appropriate action as a tornado approaches and strikes would be judged on different system levels and time scales than achieving a successful career despite growing up in poverty.

There has been much debate about the criteria by which the resilience of young people should be judged (Luthar 2006, Masten and Gewirtz 2006). Who should set the criteria? Does happiness matter? What are the best criteria for minority children in a majority culture? What if a child is doing well in one domain, e.g., friendships, but not in another, e. g., school? Many developmental investigators have focused on competence in developmental tasks as adaptive criteria. Developmental tasks are the behavioral achievements children are expected to engage in and accomplish during particular periods of development. Examples include learning to walk and talk, forming attachment bonds with caregivers, behaving appropriately in the classroom, and achieving in school. Across the life-span, these tasks change and also wax or wane in salience.

Over the past four decades, extensive empirical work has been conducted on resilience in children and youth who were exposed to a diverse array of acute and chronic, common and rare, unique and shared events and experiences. There were studies of adaptation in the context of common stressors such as divorce and poverty and community-wide disasters such as earthquakes, 9-11, the Oklahoma City bombing, brush fires, hurricanes, and school violence (Pine et al. 2005, Luthar 2006, Masten and Gewirtz 2006). Most of this research focused on the behavioral level of analysis and individual resilience in children and youth, although some investigators focused on human systems of a higher order, including family resilience (Patterson 2002) and school resilience (Wang and Gordon 1994), and on resilience in adults (Bonanno 2004). More recently, there has been a growing surge of research on resilience at biological or neurobehavioral levels of analysis (Charney 2004, Cicchetti and Curtis, 2006, 2007, Haglund et al. 2007, Masten 2007).

Literature connecting individual resilience to the adaptive functioning of larger social systems and networks, such as neighborhoods or socio-cultural systems, is very scarce. One exception is the work of Sampson and colleagues on collective efficacy in Chicago neighborhoods in relation to the outcomes of young people (Sampson et al. 1997, 2000). There has also been some research on the role of religion in resilience (see Crawford et al. 2006). Nonetheless, given the significance of cultural systems and their evolution as protective systems for human adaptation and development, there are surprisingly few resilience studies focused on cultural systems (Wright and Masten 2005).

Also striking by its absence in the scholarship on resilience in the human development literature, both conceptually and empirically, is work that embeds human development in ecosystems that include interactions among species and nonhuman systems. Very little attention has been directed to integrating the theory and science of individual human resilience in development with the broader ecological systems theory and research exemplified by a journal like Ecology and Society. 
Fig. 2. Multiple-level embedded systems that interact to influence a child's life illustrating Bronfenbrenner's $(1979,1986)$ concepts. The child as a living system is shown embedded in three microsystems, namely, family, peer group, and school. These microsystems are in turn embedded in a larger-scale systems, as shown for the school system, which is embedded in a town that is part of a larger macrosystem. Within the individual child, two inter-related internal systems are shown, i.e., the central nervous system and the immune system, each of which could be further differentiated at the cellular system level. Bronfenbrenner's concept of the exosystem is illustrated by the parent work place, which influences the child indirectly through the parent. His concept of the mesosystem refers to interactions among the microsystems of the child, for example between parent and teacher or parent and peer.

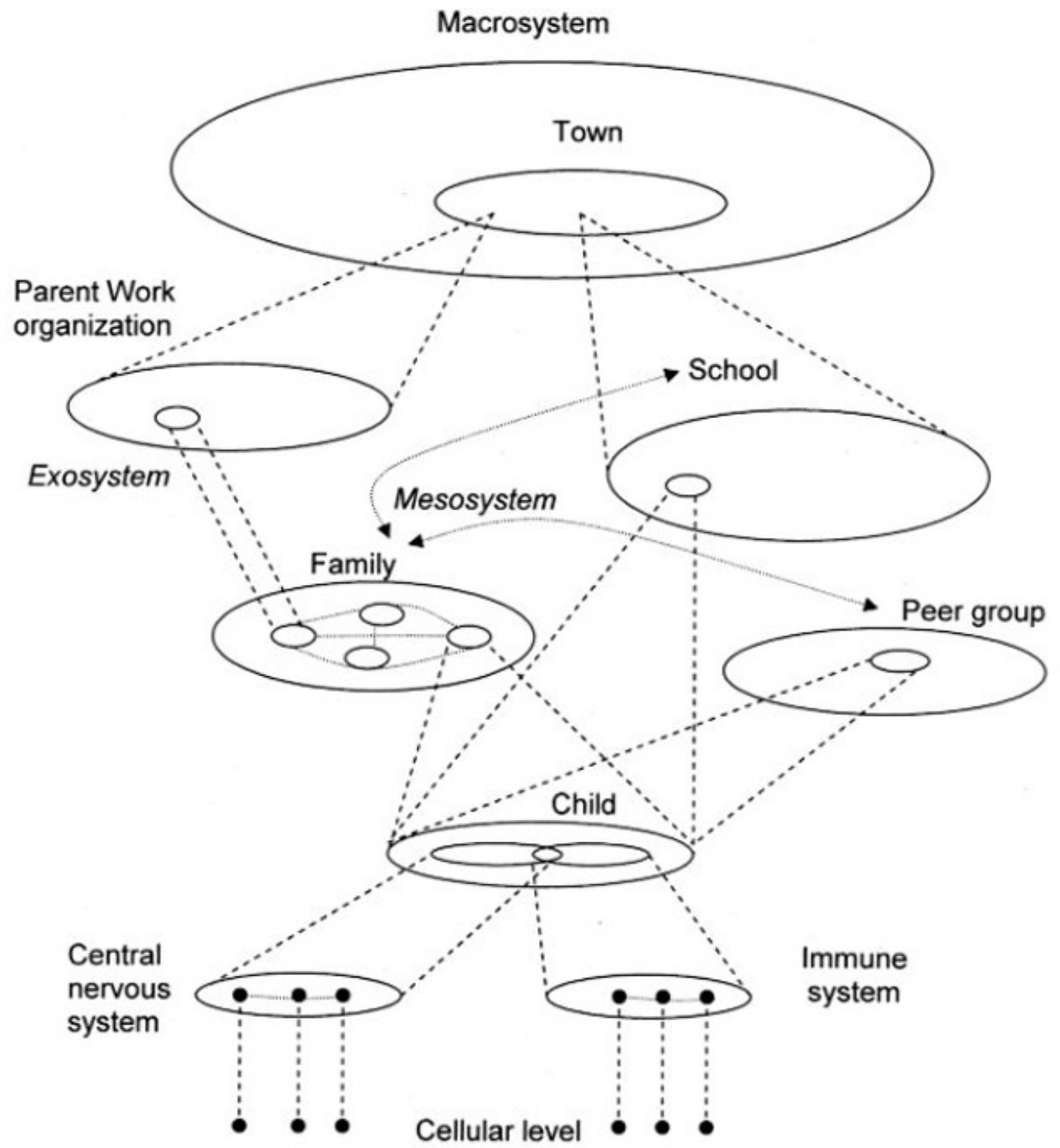




\section{Resilience theory in human developmental science compared to ecology}

Developmental resilience theory emphasizes that adaptive human development involves many interactions within and across systems, characterized by both continuity and change. These changes can appear to be discontinuous even when they are not, as in the developmental stages of a monarch transforming from caterpillar to chrysalis to butterfly, an idea known as "heterotypic continuity." Dramatic transformations occur in the course of human development, for example, during puberty, when the coherence of the individual is sustained through major changes in form and function (Masten and Obradovic 2006, Steinberg et al. 2006).

In ecology, resilience has similar connotations, referring to "the capacity of a system to absorb disturbance and reorganize and yet persist in a similar state" (Gunderson et al. 2006). This definition emphasizes persistence or recovery to a similar state somewhat more than developmental theory, in which positive, adaptive transformations are construed as one of several major classes of resilience phenomena; others are resistance and recovery. Resilience theory in ecology also appears to focus less on individual resilience; the fate of a single organism, unless it is one of the last of its kind, is rarely a subject of interest. At the same time, it is recognized in ecology that the behavior of a single human individual could have devastating consequences for a particular ecosystem, e.g., dumping toxic waste or setting off a dirty bomb.

Despite some differences in emphasis, there are striking parallels in the conceptualization of the resilience of a living human organism in developmental science and the resilience of an ecosystem in ecology, perhaps because both sciences were strongly influenced by general systems theory (von Bertalanffy 1968). In both fields, resilience emerges from dynamic interactions and change. Similarly, both fields emphasize that the direction or development of a complex system is probabilistic rather than deterministic, because of the inherently dynamic nature of living, open systems and the sheer number of interactions involved. As a consequence of complex and multicausal models, it is recognized in both disciplines that there are multiple pathways a system or individual may follow. In both perspectives, resilience processes rely on flexibility and adaptive capacity for change rather than stability or equilibrium with return to the exact same steady state. Ecological resilience and developmental resilience both focus on changes that preserve viability and adaptive flexibility for an uncertain future in which adaptive success in the face of major challenges requires change and some responsive flexibility for a system to survive or flourish. Both also recognize the role of human judgment in defining desirable or undesirable regimes or outcomes (Masten and Coatsworth 1998; L. H. Gunderson and L. Ruttan, unpublished manuscript).

The general resilience of a system, as conceived independently in human development and in ecology, is compatible with marked instability or change. However, a system may be more vulnerable to transformation during periods of intense instability or change, which are often characterized by increases in variance. In ecosystems, increases in variety have been associated with a higher likelihood of sudden transitions to new states, known as regime shifts or, more colloquially, as "flipping" states (Gunderson 2000). Developmental scientists have recognized the importance of transitional windows of concentrated change, when individual humans may be more likely to change course. Early adolescence, for example, is a period of marked change in biological, cognitive, family, school, and other systems of adolescent life, when individual adolescents may be more susceptible to disturbances that threaten healthy development but also more open to favorable change through positive influences or interventions (Dahl and Spear 2004, Masten 2004, Steinberg et al., 2006). The transition to adulthood, which is often now termed "emerging adulthood" (about 18 to 25 years old), is another window of marked change that investigators have recognized as a time when the life course often changes and when societies often attempt to shape the direction of change by providing structuring opportunities such as military service, apprenticeship, or college (Masten et al. 2006b). It is probably not a coincidence that sudden changes in life direction or personality, such as religious conversion or epiphanies concerning identity and self, occur in this developmental window.

Both developmental science and ecological science also recognize that resilience can be evaluated from general or specific points of view and from multiple levels of analysis. In developmental theory, resilience can refer to the broad status of good functioning in all expected areas or to resilience in specific domains such as educational resilience or 
emotional resilience. Moreover, it is recognized that a given individual may exhibit resilience in the face of one kind of threat and not another, or at one time in life and not another (Masten et al. 1990, Luthar 2006, Masten and Obradovic 2006). In ecosystem theory as well, general resilience and specific resilience have been delineated, often in relation to varying scales of level, space, and time (L. H. Gunderson and L. Ruttan, unpublishedmanuscript).

\section{FINDINGS FROM STUDIES OF RESILIENCE IN DEVELOPMENT}

Findings from studies of human resilience have been extensively reviewed over the years (Garmezy 1985, Masten et al. 1990, Masten and Coatsworth 1998, Luthar 2003, Bonanno 2004, Luthar 2006, Masten and Gewirtz 2006). Despite all the issues that can be expected in a young research field, the yield from this labor has been surprisingly consistent in implicating a short list of what seems to matter. Consequently, it has been proposed that most human resilience, at least in children and youth, arises from "ordinary magic" or the operation of fundamental human adaptive systems that have evolved over the course of biological and cultural evolution (Masten 2001). If these systems are operating normally, they convey considerable capacity for resilience to an individual, either to sustain or recover to good functioning. If these systems are damaged or destroyed, the potential for resilience will be compromised, a conclusion with important implications for disaster planning and triage.

\section{Fundamental adaptive systems for human resilience}

The following protective systems have been implicated repeatedly in diverse studies of resilience in children and adolescence (Masten and Coatsworth 1998, Wright and Masten 2005, Masten et al. 2006a, Masten and Gewirtz 2006). More recent studies of adults implicate similar systems, although in developmentally mature forms (Bonanno 2004, Charney 2004). These systems can be described broadly in terms of "social capital," i.e., the adaptive capacity available through relationships, and "human capital," the adaptive capacity that a human individual can muster on his or her own.

\section{Attachment}

In a recent review of resilience studies, Luthar (2006:780) concluded the following: "Resilience rests, fundamentally, on relationships." The pioneers in the field noted the essential role of human attachments in resilience, and every major review since that time has upheld their observations. For young children, adaptation and the potential for resilience depend primarily on the quality of their early relationships with parent figures. A powerful biological system is implicated in these findings, first delineated in work by John Bowlby (1969), who described the workings of the attachment system in three classic volumes on attachment and loss. Once attachment bonds have formed between a caregiver and child, typically toward the end of the first year for infants, threats to the child perceived by either the caregiver or the child will activate attachment behaviors such as proximity seeking and contact maintenance. The attachment figure provides a child with a secure base for reassurance under threat, and when conditions are relaxed, with the confidence to venture out to explore and learn about the world. Separation from attachment figures can cause extreme anxiety to the point of panic, particularly when a threat is perceived, and loss can induce profound grief. Children often form attachment bonds with multiple caregivers, siblings, pets, snuggly objects such as security blankets, and pacifiers. Separation and loss can activate attachment behaviors in any of these cases, with the largest effects elicited in relation to the primary caregiver.

Sensitive attachment figures also serve a powerful regulatory function, up- or down-regulating stress and arousal or containing impulses. This is easy to observe in parent-infant dyads playing arousal games, e.g., peek-a-boo, tossing in the air, or chase, but it has also been shown in controlled experiments. The presence of a secure-base attachment figure has been shown to moderate stress in threatening situations for infants and toddlers (Gunnar 2005). Parents also can modulate exposure to threat in multiple ways, including their monitoring of media use by children.

As children grow older, close friends and eventually committed romantic partners provide a secure base. Separation or threat to these new attachment relationships can also induce powerful feelings of anxiety or fear and a strong need to seek contact. 
After the 9-11 attack in New York, for example, it was evident that Americans of all ages, around the world, sought contact with their secure-base figures and that this seeking was mutual and multigenerational. The widely reported benefits of social support in human research on stress and coping probably depend on attachment system functions.

All planning for disaster must account for the attachment system and how such relationships are likely to motivate behavior and provide for a sense of security. Under all but the most physically lifethreatening circumstances, children usually fare better psychologically in proximity to attachment figures. This has been observed in diverse field situations ranging from the evacuations of children from London during the Blitz of World War II to Australian bush fires (Garmezy and Rutter 1983). Separation from attachment figures can cause more stress than the direct effect of catastrophe itself, although, of course, dangers and circumstances may force separations to occur (Masten et al. 1990). However, it also must be emphasized that the attachment system is not only biologically based but also bilateral. Parents, for example, will find separation from their children enormously stressful under threatening conditions and may seek proximity even if it endangers their own safety. This could pose great difficulties for enforcing and managing quarantine situations that separate family members in a pandemic or mobilizing first responders who do not know if their own children are safe.

Agency, self-efficacy, and the mastery motivation system

As noted by Robert White (1959) in his classic paper on competence and the mastery motivation system, human beings are motivated to adapt to the environment and to experience reward for perceived success. Albert Bandura (1997) elaborated on this system in his empirical work and theory concerning self-efficacy, as did other scholars in terms of intrinsic motivation or related concepts (Masten et al. 2006a). Humans, unlike less intelligent species, also develop a sense of their own agency in adaptation and its attendant rewards. As the human brain matures well into the twenties, human capacity for planning and directing adaptation and gaining control of the mastery reward system expands (Masten et al. 2006b). People with a positive view of their own efficacy, as Bandura and others have demonstrated in elegant experiments, will exert more effort to succeed and are more likely to persist in the face of adversity. People who persist are more likely to succeed, which reinforces efforts to adapt. Thus, it is not surprising to find that, from an early age, human individuals who overcome adversity report more positive views of their own effectiveness and self-worth, express more confidence about success, and experience pleasure in doing well. Adolescents in trouble, not yet resilient but who will become successful adults, begin to express motivation to change and achieve even before their resilience is manifested (Hauser et al. 2006, Masten et al. 2006b). Moreover, this system is so powerful that many individuals prefer to shoulder the responsibility for events beyond their control, rather than believe that events are completely uncontrollable.

The mastery motivation system can be extinguished by prolonged exposure to unresponsive environments or uncontrollable events, which was noted early in the research on severe deprivation effects in young children, e.g., living in cribs in barren orphanages (Zeanah et al. 2006) and also in learned helplessness experiments (Seligman 1975). It is important to consider this system in disaster planning and recovery because it is a vital engine for human action that is also self-perpetuating, powered by an inherent reward system.

\section{Intelligence: central nervous systems for problem-} solving and information processing

Historically, intelligence has been described in terms of the cognitive or mental activity associated with learning and effective adaptation (Masten et al. 2006a). Thus, it is not surprising to find that better cognitive skills and problem-solving aptitude are implicated in nearly every study comparing adaptive and maladaptive groups. Under conditions of high threat or adversity, the ability to continue thinking and planning effectively is characteristic of resilience; good intellectual skills show protective effects for children and adults dealing with adversity (Masten 2001, Luthar 2006). In our study on adversity and resilience in a school sample followed over 20 years, we found that resilient young people had much better intellectual skills than their maladaptive peers exposed to similarly high levels of adversity in childhood and adolescence, and the difference was even more striking for the youth who experienced prolonged and catastrophic levels of adversity (Masten et al. 
1999, Masten and Obradovic 2006). Extraordinary intelligence is not required, but rather a human brain in good working order and some knowledge about what is going on and what to do.

Intelligent behavior by humans in a disaster may also require high levels of interaction with nonhuman information processing systems, including computers, that serve to augment the limitations of human information capacity. To date, however, very little attention has been paid to the role of human-computer interaction in the capacity of children or their family members to respond or recover in disasters, although there is a rapidly emerging literature on the role of media in human development (Brown and Witherspoon 2002, Wartella et al. 2004).

Intelligent behavior rests on healthy brain development and functioning as well as learning processes and experience. Intelligent behavior is influenced not only by past development, learning, and experience, but also by current arousal level, stress, fatigue, illness, injury, motivation, values, emotions, and many other influences potentially altered in the course of unfolding disaster. However, good judgment in a crisis requires more than a good information-processing system. It is also important to remember that high levels of arousal can interfere with decision making, working memory, and other forms of executive functioning. The degree to which one can manage arousal and direct the resources at hand are likely to play a critical role in disaster response and resilience.

\section{Regulatory systems for controlling arousal, affect, attention, and action}

Adaptive functioning under all circumstances requires a certain degree of regulatory control to coordinate action, manage emotion, and attend efficiently. In young children, caregivers and the attachment relationship serve as auxiliary regulatory systems. In effect, parents provide "scaffolding" for the development of selfregulation. During toddler and preschool years, effortful or self-initiated control emerges supported by simultaneously developing neural mechanisms of executive attention. This emergent skill allows children to exercise control over their attention, behaviors, and emotions by inhibiting the dominant response in the service of activating the subdominant response (Eisenberg et al. 2004, Rueda et al. 2004).
Overcoming adversity often calls on self-regulation skills to continue functioning effectively under highly stressful or arousing circumstances. This is one of the most important sets of skills that emergency room staff, first responders, and airtraffic controllers must be trained for. Once again, it is not surprising to find that many aspects of voluntary self-control, e.g., voluntary self-restraint and resolving conflicts between competing feelings, thoughts, and behaviors, are associated with higher competence as well as better adaptation during and following adversity and trauma (Masten and Coatsworth 1998, Masten 2004). Nevertheless, fear and anxiety, along with other negative emotions, can influence human self-control systems and the quality of executive functioning that unfolds in a crisis. Thus, it is wise to consider the negative effects of terror, propagated by a terrorist attack or rumors, and separation anxiety from worries about attachment figures on cognitive functioning in family and community members, or first responders, in a crisis. Decision making and behavior by children, adolescents, parents, professional first responders, community leaders, and national leaders will be affected by the regulatory capabilities of individuals within each system. Moreover, affect is contagious, particularly among attached groups of people. Children, for example, find a terrified parent particularly terrifying because they use parents to gauge danger and safety, a phenomenon called "social referencing" in developmental science (Masten and Gewirtz 2006). In a crisis, parents as well as other caregivers may inadvertently allow children, as well as themselves, to be traumatized by repeated exposure to intense media coverage of disasters that are too much to handle (Pine et al. 2005). In a flu pandemic or bioterrorism incident, there will be a fear vector as well as a disease vector, and the propagation of fear through the population could threaten executive functioning systems across multiple levels of human behavior from individuals to governments. Uncontained fear spreads, and it can undermine decision making at many levels.

Microsystems, including family, peers, classroom, and work

Humans are social, and their adaptive functioning is embedded in a complex array of interdependent relationships and social systems that also serve many regulatory and protective roles. These social systems presumably have evolved through biological and cultural evolution, enhancing the survival and resilience of constituent members, 
including families or individuals. Children spend time in several major systems, including the family, peer groups, and schools, and the functional qualities of these systems are related to individual resilience in development (Masten and Coatsworth 1998, Luthar 2006, Masten and Shaffer 2006, Masten and Motti-Stefanidi 2008). The relationships discussed above in terms of attachment play a key role in how these systems work to promote resilience. These social systems also engage or foster other fundamental human adaptive systems.

Schools, for example, are explicitly charged with developing human capital, particularly the knowledge, cognition, and self-regulation skills needed to function in society. Schools also afford many opportunities for mastery experiences and the attendant rewards. However, schools play a larger and important symbolic role in many societies, which is evident in the aftermath of disaster. Welloperating schools appear to signify that a community is functionally competent; following calamity, resumption of school function can symbolize community survival.

It is also the case that children spend so much time in school that there is a high likelihood that many of them will be located there at the time of an acute disaster. For this reason, many communities now require schools to have emergency plans for all kinds of threats. The physical concentration of children in schools makes it likely that pandemics will spread quickly to affect large groups of children, their teachers, and families from the same schools. Teachers and school personnel must be considered first responders because they are so likely to be first on the scene of disasters during the school day (Pine et al. 2005). The same case can be made for all parents with children at home and all adults engaged in child care of any kind. From a child's point of view, caregivers are highly likely to be the first responders for children.

Families can be viewed as adaptive systems for each family member. In families with children, parents are charged by societies with the complex job of protecting the children in their charge from all threats, including disasters, and also for preparing them to become adaptive young people who can cope effectively with challenges. Families function in multiple ways before, during, and after a crisis to protect their members (Masten and Shaffer 2006). Developmental studies of family process have examined how family routines, rituals, beliefs, narratives, values, etc., may work to regulate and protect individuals within the family, particularly children, over and above the provider roles of food, water, shelter, etc., and attachment (Clarke-Stewart and Dunn 2006, Fiese and Spagnola 2007).

Families undoubtedly vary in their resilience, both in regard to threats from inside the family, such as domestic violence or illnesses, and threats from outside the family, such as community violence or disaster. Stressors that destroy or disrupt the family, ranging from divorce to war, can have devastating effects on children. Thus, there is a keen and growing interest in the best ways to support and protect family functioning in times of crisis and recovery. Most of these have been directed at internal threat situations via interventions such as crisis nurseries, child protection, and foster care for family violence, rather than planning support for family functioning during natural disaster, war, disease epidemics, and terrorism. Nevertheless, families are a fundamental response unit: Families typically live together, evacuate or refuse to evacuate together, worship together, etc. Parents have an important role in modulating the exposure of children, especially young children, to threats, particularly media exposure, as noted above. With infectious diseases, they often infect each other before any individual is diagnosed. They also infect each other with fear. The apparent lack of consideration and support at the family level in disaster planning is surprising given family responsibilities and the ease with which they can be reached through connections with schools, neighborhoods, medical facilities, grocery stores, and other local settings.

As individuals grow older, additional social systems play an important role in resilience for individuals. These cannot be discussed because of space limitations, but they include many kinds of social groups ranging from religious groups to adolescent cliques or clubs and civic and work organizations. All social groups hold the potential for providing social capital and augmenting the adaptive capacity of the individuals in the group. Of course, groups also can spread fear, violence, infections, and maladaptive behaviors. Gangs have a penchant for hijacking adaptive systems in the service of violence and other antisocial goals.

\section{Community-level systems and collective efficacy}

Studies of human resilience have hinted at the role of community-level resources and collective efficacy in explaining individual or family 
resilience. However, it is a challenging task to distinguish neighborhood- or community-level effects from the role of individual functioning or family, peer, school, and other systems embedded in communities. The most compelling examination of the collective efficacy of communities and the corresponding resilience of their constituents has been carried out by Sampson and colleagues (1997, 2000). There clearly is a need to link the study of resilience in individuals and families to the resilience of the larger social systems in which they are embedded, such as urban neighborhoods and public health systems (D. Wallace and R. Wallace, unpublished manuscript).

\section{Macrosystems: Culture, media, and national and international organizations}

Although the roles of cultural systems, mass media, and other systems that extend well beyond communities have been acknowledged and discussed in theories or descriptions of human resilience (Masten and Gewirtz 2006), these influences are rarely incorporated into behavioral studies. In large part, this neglect may be because of traditional disciplinary boundaries, in that the behavioral scientists and now the neuroscientists who focus on human resilience lack the requisite expertise in macrosystem theory and methods. In addition, behavioral scientists have given remarkably little empirical attention to the interdependence of human information processing in children and families in relation to other communication systems, particularly in relation to interactions with computers and media. Resilience in human individuals in disaster will be influenced not only by the availability of information and the ability to communicate with members of attachment networks but also by judgments of trustworthiness of information sources and skills in understanding and using the information and information technologies (Chin et al. 2004, Longstaff 2005; Longstaff and Yang 2008).

Perhaps the best examined of the macrosystems in studies of adult resilience has been religion and spirituality tied to culture (Haglund et al. 2007). Indeed, religions instantiate many of the same protective systems implicated in resilience research (Crawford et al. 2006). For example, humans appear to form attachment-like relationships with spiritual figures and religious leaders that may provide a secure base analogous to a parent attachment. Religious beliefs and practices also mobilize many of the adaptive systems discussed above, such as self-regulation through prayer or meditation, or social support and regulation through rituals, ceremonies, and rules for living (Crawford et al. 2006).

\section{MOVING TOWARD A RESILIENCE FRAMEWORK FOR DISASTER PLANNING}

Preparing a large population for any kind of disaster will require a developmental perspective on human resilience, risk, and vulnerability, as well as the integration of ideas on resilience from the sciences of communication, engineering, computing, public health, and ecology, among others. Toward this goal, we offer a list of guiding principles based on research on resilience in human development. These principles, derived from the literature on resilience in the face of adversity among children and families, may provide a useful starting point in the formulation of a resilience framework for disaster planning.

\section{The nature of the threat must be considered.}

Both children and adults show a dose-response gradient to threats, with many variables influencing the dose exposure. More severe reactions occur, for example, when many threats pile up in a short time period, when events threaten basic security, e.g., a parent is threatened or killed, when trusted attachment figures show great terror signaling extreme threat, when there is greater violence or threat of bodily harm, and so forth (see Pine et al. 2005). This principle is consistent with the theme of "when resilience fails" in the ecology literature (see Longstaff 2005).

Developmental timing of experiences will influence the reactions of all human participants, including children, parents, and other adults.

Normative capabilities, resources, and vulnerabilities all shift over the course of development. Some improve or decline as a function of development, as when cognition improves or declines with brain development or dementia. Young infants may be less susceptible than adolescents to some kinds of threat, because they are completely unaware of what is happening but more dependent on the functioning of their parents for survival. Adolescents have more skills, more friends, and more community knowhow, but also greater awareness of the full 
implications of a catastrophe for their lives and future. Parents of young children will worry about different issues than parents of grown children. Aging citizens will experience and be impacted differently than younger citizens by the same kind of disaster. Changing perceptions, cognitions, resources, roles, and responsibilities, all of them related to development, are likely to influence the reaction of human individuals to catastrophe.

Experiences and responses of individuals will be influenced by the functioning of the systems in which their lives are embedded, and particularly by the behavior of people they trust or who function as a secure base in an attachment relationship.

The perceptions of children about events are influenced by the adults and peers around them, particularly those they trust. Young people use respected adults and peers as sources of information in social referencing processes. Parents, peers, and other people in the immediate microsystems in which children live their daily lives will serve as first responders in the immediate aftermath of disaster. It is particularly important how adults function in their everyday contexts, because their behavior itself will serve to model, exacerbate, or buffer the impact of disaster on children. The attachment system presumably evolved to draw caregiving adults and their dependents into proximity for just this sort of secure-base protection. Under perceived threat, humans and other social species in attachment relationships will seek proximity with each other for comfort and protection.

The functioning of individuals in families, peer groups, and larger systems will be influenced by their perceptions of the safety of other system members, particularly by the well-being of people in their close attachment relationships.

This is a corollary of the third principle. The attachment system operates bidirectionally, such that a threat to any attachment figure will arouse a response from those who are part of the attachment network of the individual.

It is important to identify the most likely first responders for vulnerable populations.

In the case of children, for example, parents, teachers, and day-care providers are the most likely first responders. Disaster planning must consider this simple reality.
Preparations and interventions need to consider the interdependence and multiplicity of systems of human lives.

Human life is embedded in many other systems external to the individual organism and also influenced by many systems internal to the individual organism. As a result, there may be many levels and strategies for altering how one individual or a group of individuals functions, ranging from medicine to media. It is likely that there are better and worse levels or timing or methods for promoting a particular change at a particular time for a particular person or system. Concomitantly, it is unlikely that there is one "magic bullet" or the "right stuff" for resilience, given the enormous diversity and complexity of systems involved. Thus, it is important to consider diverse levels and strategies for preparation and intervention, as well as the possibility of matching interventions to individual and contextual differences (see also Longstaff 2005).

All first responders need to know what responses to disaster can be expected at all levels of human development and the best practices for psychological and physical first aid.

All major disasters will involve, directly or indirectly, human responses to disaster. It will be important for first responders to know what to expect about human response across the life-span, as well as some basic strategies and guidelines for reducing threat impact and promoting resilience.

\section{CONCLUSIONS}

In the event of a flu pandemic, bioterrorism, a natural disaster, or any other large-scale catastrophe, the best surveillance, equipment, communication systems, antiviral supplies, military, and emergency services in the world will not be effective without equal attention to the issues posed by human behavior under conditions of lifethreatening danger to children and families. The burgeoning research on human resilience, which began with a focus on children and families in the middle of the 20th century, offers important principles and guidelines for planning and recovery. The adaptive systems for positive human adaptation and development, legacies of biological and cultural evolution, must be considered and enjoined to promote resilience. 
It is often argued that "all disasters are local," at least in the short term. In the same sense, it could be said that all human resilience is local, emerging from the actions of individuals and small groups of people, in relation to each other and powered by the adaptive systems of human life and development. Larger systems facilitate this resilience, but are not likely to be directly available during an unfolding disaster on the scale of a flu pandemic or unfolding natural disaster, when some key communication, transportation, manufacturing, and other systems are likely to be disrupted or destroyed (Longstaff 2005). However, macrosystems such as governments, media, and religions do have a functional presence in the expectations, values, hopes, training, and knowledge that individuals and local families in communities carry with them all the time, particularly in their memories and know-how. Moreover, individuals and families will consult and support each other over long distances through electronic communication if it is available. Individuals will seek contact with their secure-base figures, wherever they are, by whatever means are at hand. Ideally, first responders must know that their own attachment figures will be as safe as possible to function with full effectiveness. Communication systems must allow for contact among families as well as other types of emergency contact. Perhaps it is time for a free-access, highspeed information interstate highway system and a reliable Web-based emergency portal to a virtual place for families and friends to find each other and connect.

Effective preparation for and response to the looming threats of the 21 st century require a new level of integration of knowledge of resilience across interdependent systems and across scales. Knowledge from research on human resilience from the developmental and behavioral sciences must be integrated with knowledge about resilience from research on many other components of the complex interacting systems in which human life is embedded. Mobilization to prepare, respond, and recover effectively from major disasters requires a full-scale collaborative and multidisciplinary agenda to integrate ways of understanding and changing the dynamics of resilience from molecules, microbes, and microchips to cities, societies, economies, electronic communities, and ecosystems.
Responses to this article can be read online at:

http://www.ecologyandsociety.org/voll3/iss 1/art9/responses/

\section{Acknowledgments:}

We gratefully acknowledge the recent support of the National Science Foundation (under Grant No. 0524157) in funding the meetings of the network on "Building an Interdisciplinary Study of Resilience" (Patricia Longstaff, PI), which inspired this article. Our work on resilience in human development also has been supported over the years by the William T. Grant Foundation, the National Institute of Mental Health, the National Institute on Child Health and Development, and the University of Minnesota, through a number of grants and fellowships.

\section{LITERATURE CITED}

Bandura, A. 1997. Self-efficacy: the exercise of control. Freeman, New York, New York, USA.

Bonanno, G. A. 2004. Have we underestimated the human capacity to thrive after extremely aversive events? American Psychologist 59(1):20-28.

Bowlby, J. 1969. Attachment and loss. Basic Books, New York, New York, USA.

Bronfenbrenner, U. 1979. The ecology of human development: experiments by nature and design. Harvard University Press, Cambridge, Massachusetts, USA.

Bronfenbrenner, U. 1986. Ecology of the family as a context for human development: research perspectives. Developmental Psychopathology 22 (6):723-742.

Brown, J. D., and E. M. Witherspoon. 2002. The mass media and American adolescents' health. Journal of Adolescent Health 31:153-170.

Charney, D. 2004. Psychobiological mechanisms of resilience and vulnerability: implications for successful adaptation to extreme stress. American Journal of Psychiatry 161:195-216.

Chin, S.-K., P. Humenn, T. Kosiyatrackul, T. Northrup, S. Older, and S. Thorson. 2004. A 
trusted information sharing project. Available online at: www.ecs.syr.edu/faculty/chin/papers/SK M2004.pdf.

Cicchetti, D., and W. J. Curtis. 2006. The developing brain and neural plasticity: implications for normality, psychopathology, and resilience. Pages 1-64 in D. Cicchetti and D. J. Cohen, editors. Developmental psychopathology. Volume 2. Developmental neuroscience. Second edition. Wiley, Hoboken, New Jersey, USA.

Cicchetti, D., and W. J. Curtis, editors. 2007. Special issue: a multilevel approach to resilience. Development and Psychopathology 19(3).

Clarke-Stewart, A., and J. Dunn, editors. 2006. Families count: effects on child and adolescent development. Cambridge University Press, New York, New York, USA .

Crawford, E., M. O. Wright, and A. S. Masten. 2006. Resilience and spirituality in youth. Pages 355-370 in E. C. Roehlkepartain, P. E. King, L. Wagener, and P. L. Benson, editors. The handbook of spiritual development in childhood and adolescence. Sage, Newbury Park, California, USA.

Dahl, R. E., and L. P. Spear, editors. 2004. Adolescent brain development: vulnerabilities and opportunities. New York Academy of Sciences, New York, New York, USA.

Eisenberg, N., C. L. Smith, A. Sadovsky, and T. L. Spinrad. 2004. Effortful control: relations with emotion regulation, adjustment, and socialization in childhood. Pages 259-282 in R. F. Baumeister and K. D. Vohs, editors. Handbook of self-regulation: research, theory, and applications. Guilford, New York, New York, USA.

Fiese, B. H., and M. Spagnola. 2007. The interior life of the family: looking from the inside out and the outside in. Pages 119-150 in Developmental psychopathology: integrating multiple systems and levels of analysis. University of Minnesota, Minneapolis, Minnesota, USA.

Ford, D. H., and R. M. Lerner. 1992. Developmental systems theory: an integrative approach. Sage, Newbury Park, California, USA.

Garmezy, N. 1985. Stress-resistant children: the search for protective factors. Pages 213-233 in J. E. Stevenson, editor. Recent research in developmental psychopathology. Journal of Child Psychology and Psychiatry Book Supplement No. 4. Pergamon, Oxford, UK.

Garmezy, N., and M. Rutter. 1983. Stress, coping and development in children. McGraw-Hill, New York, New York, USA.

Gunderson, L. H. 2000. Ecological resilience in theory and application. Annual Review of Ecological Systems 31:425-439.

Gunderson, L. H., C. Folke, and M. Janssen. 2006. Generating and fostering novelty. Ecology and Society 11(1): 50. [online] URL: http://www.ec ologyandsociety.org/vol11/iss1/art50/.

Gunnar, M. R. 2005. Social regulation of stress in early child development. Pages 106-125 in K. McCartney and D. A. Phillips, editors. Handbook of early child development. Blackwell, London, UK.

Haglund, M. E. M., P. S. Nestadt, N. S. Cooper, S. M. Southwick, and D. S. Charney. 2007. Psychobiological mechanisms of resilience: relevance to prevention and treatment of stressrelated psychopathy. Development and Psychopathology 19(3):889-920.

Hauser, S. T., J. P. Allen, and E. Golden. 2006. Out of the woods: tales of resilient teens. Harvard University Press, Cambridge, Massachusetts, USA.

Holling, C. S. 1973. Resilience and stability of ecological systems. Annual Review of Ecological Systems 4:1-23.

Lerner, R. M. 2006. Developmental science, developmental systems, and contemporary theories. Pages 1-17 in W. Damon and R. M. Lerner, editors. Theoretical models of human development. Volume 1. Handbook of child psychology. Sixth edition. Wiley, Hoboken, New Jersey, USA.

Longstaff, P. H. 2005. Security, resilience, and communication in unpredicatable environments such as terrorism, natural disaster, and complex technology. Harvard University Program on Information Resources Policy, Cambridge, Massachesetts, USA.

Longstaff, P. H., and S. Yang. 2008. 
Communication and trust: keys for building resilience to "surprises" such as natural disaster, pandemic flu, and terrorism. Ecology and Society 13, in press.

Luthar, S. S., editor. 2003. Resilience and vulnerability: adaptation in the context of childhood adversities. Cambridge University Press, New York, New York, USA.

Luthar, S. S. 2006. Resilience in development: a synthesis of research across five decades. Page 739-795 in D. Cicchetti and D. J. Cohen, editors. Developmental psychopathology. Volume 3. Risk, disorder, and adaptation. Second edition. Wiley, New York, New York, USA.

Masten, A. S. 2001. Ordinary magic: resilience processes in development. American Psychologist 56(3):227-238.

Masten, A. S. 2004. Regulatory processes, risk and resilience in adolescent development. Annals of the New York Academy of Sciences 1021:310-319.

Masten, A. S. 2006. Developmental psychopathology: pathways to the future. International Journal of Behavioral Development 31:46-53.

Masten, A.S. 2007. Resilience in developing systems: progress and promise as the fourth wave rises. Development and Psychopathology 19:921-930.

Masten, A. S., K. M. Best, and N. Garmezy. 1990. Resilience and development: contributions from the study of children who overcome adversity. Development and Psychopathology 2:425-444.

Masten, A. S., K. B. Burt, and J. D. Coatsworth. 2006a. Competence and psychopathology in development. Pages 696-738 in D. Ciccheti and D. Cohen, editors. Developmental psychopathology. Volume 3. Risk, disorder, and adaptation. Second edition. Wiley, New York, New York, USA.

Masten, A. S., and J. D. Coatsworth. 1998. The development of competence in favorable and unfavorable environments: lessons from research on successful children. American Psychologist 53 (2):205-220.

Masten, A. S., and A. H. Gewirtz. 2006. Vulnerability and resilience in early child development. Pages 22-43 in K. McCartney and D. A. Phillips, editors. Handbook of early childhood development. Blackwell, Malden, Massachusetts, USA.

Masten, A. S., J. Hubbard, S. D. Gest, A. Tellegen, N. Garmezy, and M. Ramirez. 1999. Adversity, resources and resilience: pathways to competence from childhood to late adolescence. Development and Psychopathology 11:143-169.

Masten, A. S., and F. Motti-Stefanidi. 2008. Understanding and promoting resilience in children: promotive and protective processes in schools. In T. Gutkin and C. Reynolds, editors. The handbook of school psychology. Fourth edition. Wiley, New York, New York, USA, in press.

Masten, A. S., and J. Obradovic. 2006. Competence and resilience in development. Annals of the New York Academy of Sciences 1094:13-27.

Masten, A. S., J. Obradovic, and K. B. Burt . 2006 b. Resilience in emerging adulthood: developmental perspectives on continuity and transformation. Pages 173-190 in J. J. Arnett and J. L. Tanner, editors. Emerging adults in America: coming of age in the 21st century. American Psychological Association Press, Washington, D. C., USA.

Masten, A. S., and A. Shaffer. 2006. How families matter in child development: reflections from research on risk and resilience. Pages 5-25 in A. Clarke-Stewart and J. Dunn, editors. Families count: effects on child and adolescent development. Cambridge University Press, Cambridge, UK.

Patterson, J. 2002. Understanding family resilience. Journal of Clinical Psychology $\mathbf{5 8}$ (3):233-246.

Pine, D. S., J. Costello, and A. S. Masten. 2005. Trauma, proximity, and developmental psychopathology: the effects of war and terrorism on children. Neuropsychopharmacology 30:1781-1792.

Rueda, M. R., M. I. Posner, and M. K. Rothbart. 2004. Attentional control and self-regulation. Pages 283-300 in R. F. Baumeister and K. D. Vohs, editor. Handbook of self-regulation: research, theory, and applications. Guilford, New York, New York, USA. 
Sampson, R. J., S. W. Raudenbush, and F. Earls. 1997. Neighborhoods and violent crime: a multilevel study of collective efficacy. Science 277:918-924.

Sampson, R. J., G. D. Squires, and M. Zhou. 2000. How neighborhoods matter: the value of investing at the local level. American Psychological Association Press, Washington, D.C., USA.

Seligman, M. E. P. (1975). Helplessness: on depression, development, and death. Freeman, San Francisco, California, USA.

Steinberg, L., R. E. Dahl, D. Keating, D. J. Kupfer, A. S. Masten, and D. S. Pine. 2006. Psychopathology in adolescence: integrating affective neuroscience with the study of context. Pages 710-741 in D. Ciccheti and D. Cohen, editors. Developmental psychopathology. Volume 2. Developmental neuroscience. Second edition. Wiley, New York, New York, USA.

Thelen, E., and L. Smith. 1998. Dynamic systems theories. Pages 563-634 in R. M. Lerner, editor. Handbook of child psychology. Volume 1. Theoretical models of human development. Fifth edition. Wiley, New York, New York, USA.

von Bertalanffy, L. 1968. General system theory: foundation, development, applications. Braziller, New York, New York, USA.

Wang, M. C., and E. W. Gordon. 1994. Educational resilience in inner-city America: challenges and prospects. Erlbaum, Hillsdale, New Jersey, USA.

Wartella, E., A. G. Caplovitz, and J. H. Lee. 2004. From Baby Einstein to Leapfrog, from Doom to the Sims, from instant messaging to Internet chat rooms: public interest in the role of interactive media in children's lives. Social Policy Report 18 (4):3-18.

White, R. 1959. Motivation reconsidered: the concept of competence. Psychological Review 66:297-333.

Wright, M. O., and A. S. Masten. 2005. Resilience processes in development: fostering positive adaptation in the context of adversity. Pages 17-37 in S. Goldstein and R. Brooks, editors. Handbook of resilience in children. Kluwer Academic/Plenum,
New York, New York, USA.

Zeanah, C. H., A. T. Smyke, and L. D. Settles. 2006. Orphanages as a developmental context for early childhood. Pages 224-254 in K. McCartney and D. Phillips, editors. Blackwell handbook of early childhood development. Blackwell, Malden, Massachusetts, USA. 